\title{
Amylin mimetic
}

National Diabetes Information Clearinghouse (NDIC)

\section{Definitions}

Diabetes

Defined by National Diabetes Information Clearinghouse (NDIC)

Amylin

Defined by National Diabetes Information Clearinghouse (NDIC)

Liver

Defined by National Diabetes Information Clearinghouse (NDIC)

Glucose

Defined by National Diabetes Information Clearinghouse (NDIC)

\section{Source}

National Diabetes Information Clearinghouse (U.S.). (2009). The diabetes dictionary. [Bethesda, Md.]: U.S. Dept. of Health and Human Services, National Institutes of Health, National Institute of Diabetes and Digestive and Kidney Diseases, National Diabetes Information Clearinghouse.

A type of injectable medicine for diabetes that mimics the effect of the hormone amylin. This medicine helps food move more slowly through the stomach and helps keep the liver from releasing stored glucose. (Generic name/Brand name: pramlintide acetate/Symlin.) 